\title{
Evaluation of in vitro culture systems for the maintenance of microfilariae and infective larvae of Loa loa
}

Denis Zofou ${ }^{1,2+}$, Fanny Fri Fombad ${ }^{1,3+}$, Narcisse V. T. Gandjui ${ }^{1,3+}$, Abdel Jelil Njouendou, ${ }^{1,3+}$, Arnaud Jonas Kengne-Ouafo, ${ }^{1,3}$, Patrick W. Chounna Ndongmo ${ }^{1,3}$, Fabrice R. Datchoua-Poutcheu', Peter A. Enyong ${ }^{1}$, Dizzle Tayong Bita ${ }^{1,3}$, Mark J. Taylor $^{4}$, Joseph D. Turner ${ }^{4}$ and Samuel Wanji ${ }^{1,3^{*+}}$ (D)

\begin{abstract}
Background: Suitable and scalable in vitro culture conditions for parasite maintenance are needed to foster drug research for loiasis, one of the neglected tropical diseases which has attracted only limited attention over recent years, despite having important public health impacts. The present work aims to develop adequate in vitro culture systems for drug screening against both microfilariae ( $\mathrm{mf}$ ) and infective third-stage larvae (L3) of Loa loa.
\end{abstract}

Methods: In vitro culture conditions were evaluated by varying three basic culture media: Roswell Park Memorial Institute (RPMI-1640), Dulbecco's modified Eagle's medium (DMEM) and Iscove's modified Dulbecco's medium (IMDM); four sera/ proteins: newborn calf serum (NCS), foetal bovine serum (FBS), bovine serum albumin (BSA) and the lipid-enriched BSA (AlbuMax ${ }^{\otimes}$ II, ALB); and co-culture with the Monkey Kidney Epithelial Cell line (LLC-MK2) as a feeder layer. The various culture systems were tested on both $\mathrm{mf}$ and $\mathrm{L} 3$, using survival (\% motile), motility ( $T_{90}=$ mean duration (days) at which at least $90 \%$ of parasites were fully active) and moulting rates of $L 3$ as the major criteria. The general linear model regression analysis was performed to assess the contribution of each variable on the viability of Loa loa L3 and microfilarie. All statistical tests were performed at 95\% confidence interval.

Results: Of the three different media tested, DMEM and IMDM were the most suitable sustaining the maintenance of both $\mathrm{L}$. loa L3 and mf. IMDM alone could sustain L3 for more than 5 days $\left(T_{90}=6.5 \pm 1.1\right.$ day). Serum supplements and LLC-MK2 co-cultures significantly improved the survival of parasites in DMEM and IMDM. In co-cultures with LLC-MK2 cells, L. loa mf were maintained in each of the three basic media ( $T_{90}$ of 16.4-19.5 days) without any serum supplement. The most effective culture systems promoting significant moulting rate of $L 3$ into $L 4$ (at least $25 \%$ ) with substantial maintenance time were: DMEM + BSA, DMEM + NCS, DMEM-AlbuMax®I, DMEM + FBS all in co-culture with LLC-MK2, and IMDM + BSA (1.5\%) , DMEM + FBS (10\%) and DMEM + NCS (5\%) without feeder cells. DMEM + 1\% BSA in co-culture scored the highest moulting rate of 57 of $81(70.37 \%)$. The factors that promoted $L$. loa $\mathrm{mf}$ viability included feeder cells $(\beta=0.490)$, both IMDM $(\beta=0.256)$ and DMEM $(\beta=0.198)$ media and the protein supplements NCS $(\beta=0.052)$ and FBS $(\beta=0.022)$; while for $L$. loa $L 3$, in addition to feeder cells $(\beta=0.259)$ and both IMDM $(\beta=0.401)$ and DMEM $(\beta=0.385)$ media, the protein supplements BSA $(\beta=0.029)$ were found important in maintaining the worm motility.

(Continued on next page)

\footnotetext{
* Correspondence: swanji@yahoo.fr

${ }^{\dagger}$ Equal contributors

${ }^{1}$ Research Foundation for Tropical Diseases and Environment (REFOTDE),

South West Region, Buea, Cameroon

${ }^{3}$ Parasites and Vectors Biology Research Unit (PAVBRU), Department of

Microbiology and Parasitology, Faculty of Science, University of Buea, South

West Region, Buea, Cameroon

Full list of author information is available at the end of the article
}

(c) The Author(s). 2018 Open Access This article is distributed under the terms of the Creative Commons Attribution 4.0 International License (http://creativecommons.org/licenses/by/4.0/), which permits unrestricted use, distribution, and reproduction in any medium, provided you give appropriate credit to the original author(s) and the source, provide a link to the Creative Commons license, and indicate if changes were made. The Creative Commons Public Domain Dedication waiver (http://creativecommons.org/publicdomain/zero/1.0/) applies to the data made available in this article, unless otherwise stated. 
(Continued from previous page)

Conclusions: The findings from this work display a range of culture requirements for the maintenance of Loa loa stages, which are suitable for developing an effective platform for drug screening.

Keywords: Loa loa, L3 larvae, Microfilariae, In vitro culture system, Viability, Moulting

\section{Background}

Loiasis is a parasitic disease caused by the filarial nematode Loa loa that is transmitted through the bite of an infected Chrysops fly. Loiasis is endemic in the rainforest areas of West and Central Africa [1]. The common clinical signs of loiasis are the subconjunctival migration of the adult worm, reported for the first time by Mongin in 1770 [2], Calabar Swelling, pruritis, oedemas and arthralgia. Interest in this filarial species, which has long been considered to be less pathogenic than related species [3], came from several reports in Cameroon indicating that high microfilaraemia of $L$. loa is associated with severe and sometimes fatal encephalopathic reactions in patients who had taken ivermectin for onchocerciasis treatment [4-7]. Loiasis is a neglected tropical disease (NTD) which has attracted only limited attention in drug research and development. Apart from surgical removal of adult worms moving under the skin or across the eye that can be done to relieve anxiety, only two medications have so far been employed for clinical cases since the last century, namely diethylcarbamazine (DEC) and albendazole. The latter is sometimes used in patients who are not cured with multiple DEC treatments. Several cases of brain inflammation, coma and death have been reported in people with heavy infections when they are treated with DEC $[8,9]$. The risk of side effects has limited the deployment of mass drug administration of ivermectin in areas where the $L$. loa prevalence exceeds $20 \%$ [10-12], impeding the goals stated by the African Programme for Onchocerciasis Control (APOC) in areas of co-endemicity. Progress in drug research and development for loiasis requires suitable screening systems both at in vitro and in vivo levels. Though innovations in filarial animal models have recently been achieved [13, 14], in vitro maintenance systems of the different stages of $L$. loa have not been established. The present study aimed to design suitable in vitro culture systems for drug screening against both infective larvae (L3) and microfilariae (mf) of L. loa.

\section{Methods}

\section{Isolation and purification of $L$. loa $\mathrm{L} 3$}

Loa loa L3 were obtained from dissected Chrysops flies that had previously fed on a consented microfilaremic individual at Ediki Forest (South West region, Cameroon). Engorged Chrysops were kept in captivity for 12 days, to allow development to the infective stage
(L3). The flies were fed daily with $15 \%$ sucrose solution soaked in cotton wool. After 12 days of rearing, the flies were dissected in Petri dishes containing RPMI 1640 medium (Sigma-Aldrich, St Louis, USA). The head, thorax and abdomen were separated and teased apart in three different Petri dishes. Fly tissues were incubated for $20 \mathrm{~min}$ to allow L3 larvae to migrate out. A sterile pipette was used to pick the larvae and pooled in a shallow convex glass dish [15]. The worms were transferred into $15 \mathrm{ml}$ centrifuge tubes (Corning, Kennebunk-ME, USA) for purification. Only L3 harvested from the head (where more mature larvae are expected to be found) were used in this study. The remaining larvae were frozen to be used in other studies (immunology and molecular biology). The L3 were washed using a Percoll ${ }^{\circ}$ (GE Healthcare, Pharmacia, Uppsala, Sweden) technique. The L3 suspension concentrated in less than $1 \mathrm{ml}$ RPMI was slowly layered on the surface of a $15 \mathrm{ml}$ tube containing stock iso-osmotic Percoll $^{\circ}$ and centrifuged (Humax 14k human, Germany) at $800 \times \mathrm{rpm}$ for $10 \mathrm{~min}$. The process was repeated to remove microbial contaminants. At the end, the L3 were washed twice with RPMI1640 by centrifugation at $1500 \times \mathrm{rpm}$ for $10 \mathrm{~min}$ to remove Percoll ${ }^{\circ}$ remnant.

\section{Isolation and purification of $L$. loa $\mathrm{mf}$}

Loa loa $\mathrm{mf}$ were obtained from baboons (Papio anubis) experimentally infected with human strain of $L$. loa reared in Kumba Medical Research Station (South West region, Cameroon). Peripheral blood samples of hypermicrofilaraemic baboons were collected as described in the previous reports [13]. Microfilaraemic loads were determined microscopically on thick films. Calibrated thick blood smears were prepared by spreading a $50 \mu \mathrm{l}$ venous blood sample from a $75 \mu \mathrm{l}$ non-heparinised capillary tube, onto a clean slide over an area of $1.5 \times 2.5 \mathrm{~cm}$ [16]. After drying, films were dehemoglobinized and stained with Giemsa. The Percoll ${ }^{\circ}$ density centrifugation method previously described [17] was used to purify $\mathrm{mf}$ from infected blood samples.

\section{In vitro culture of parasites}

Four supplements were used at 3 concentrations each: fetal bovine serum (Lonza) and newborn calf serum (Sigma-Aldrich, Berlin, Germany) at $15 \%, 10 \%$ and 5\%; bovine serum albumin (Sigma-Aldrich, Berlin, Germany) and AlbuMax II (Gibco Life Technologies, Cergy- 
Pontoise, France) at $1.5 \%, 1 \%$ and $0.5 \%$. Three basic media were used: RPMI-1640 and IMDM (Sigma-Aldrich, St Louis, USA) and DMEM (Gibco Life Technologies, Cergy-Pontoise, France). Ciprofloxacin $(5 \mu \mathrm{g} / \mathrm{ml})$ was used as antibiotic and fluconazole $(10 \mu \mathrm{g} / \mathrm{ml})$ as antifungal. Flat bottom culture plates (48-well) with lids (Corning, Kennebunk, ME, USA) were loaded as follows: $800 \mu \mathrm{l}$ of the different media with a range of 20-30 microfilariae or 10-15 larvae per well. Cultures were carried out in triplicates.

\section{Monkey kidney cell co-culture}

Monkey kidney epithelial cells (LLC-MK ${ }_{2}$ ) (ATCC, USA) were cultured in flasks at $37{ }^{\circ} \mathrm{C}$ in a $\mathrm{CO}_{2}$ incubator (Sheldon Mfg. Inch, Cornelius, OR, USA) at 5\% $\mathrm{CO}_{2}$ until the cell layer became fully confluent. For new inoculations and other cell manipulations, trypsin was used to detach cells from the walls of the flasks. Cells were then dislodged with trypsin solution (25\%) containing EDTA, the mixture was kept at $37{ }^{\circ} \mathrm{C}$ for less than $1 \mathrm{~h}$. The cell suspension was centrifuged at $1,500 \mathrm{rpm}$ for 10 min, the supernatant was discarded, and the pellet resuspended and diluted to $10^{5}$ cells $/ \mathrm{ml}$ in complete culture medium. Aliquots $(100 \mu \mathrm{l})$ of cell suspensions were plated into a 48-well culture plate and kept in the incubator for cells to become fully confluent.

\section{Assessment of parasite viability}

The viability of the parasites was assessed daily, by visual inspection (by two individuals) under an inverted microscope until they die. Their motility was scored on a 4point scale $[18,19]$ : 0 , no movement or immotile; 1 , intermittent shaking of head and tail; 2, sluggish (shaking of the whole worm on a spot); 3, vigorous movement (shaking of the whole worm and migration from one spot to was considered).

\section{Data processing and analysis}

Three different batches of L3 larvae and microfilariae were used for each culture system. For each batch of parasites, 4 replicate wells were used per system. Raw data collected daily on record sheets were entered into a template designed on Microsoft Excel 2007. Three variables were defined and computed to assess the viability of the parasites (mean motility and mean mortality, $\mathrm{T}_{90}$ ).

Motility variable was computed based on the scoring system described above, and using the following formula.

$$
\text { Motility }(\%)=\frac{\sum \mathrm{SiNi}}{3 \cdot \sum \mathrm{Ni}} \times 100
$$

where $\mathrm{Si}$ is the score of point scale $\mathrm{i}$ and $\mathrm{Ni}$ is the total number of worms at a point scale i.

The variable $\mathrm{T}_{90}$ was defined as the duration at which $90 \%$ of the worms were still fully active (score 3 above) in the well. This variable was set as one of the major indicators of the suitability of the culture system, with relevance to drug screening for loiasis. From values obtained after testing each system on three batches of parasites, $T_{90}$ values were expressed as mean \pm standard deviation.

The Kruskal-Wallis test was used to assess the global significant differences between the distribution of the median $\mathrm{T}_{90}$ across media and supplements, and the pairwise multiple comparisons of the ranked data was performed using the Pairwise Multiple Comparisons of Mean Rank $(P C M R)$ package in $\mathrm{R}$ version 3.1.4. Mann-Whitney U-test was used to compare the the medians of the $\mathrm{T}_{90}$ between the cell free and cell containing culture. Statistical tests were interpreted using a 5\% significance level. It was considered that a valid appreciation of the effect of any drug could be possible only in a system where at least $90 \%$ of parasites motility were sustained till the end of the experiment.

Factors that promoted parasite survival were identified using the multiple linear regression. The general linear model (GLM) was built using the hierarchical stepwise method. A total of 5 blocks were achieved with the 5 factors (incubation time, presence of feeder cells, basic medium, serum/protein, protein concentration) and those that contributed significantly to the improvement of the model were identified based on the $F$-statistics and the adjusted $R$-square (Additional file 1: Table S1). The incubation time was treated as a metric factor. Dichotomous variables such as the presence of monkey kidney cells were coded using binary figures. For each nominal or ordinal factor (Basic culture media, protein or protein concentration), sets of dummy variables were created and compared to one of the categories defined as reference. While RPMI-1640 was used as a reference against DMEM and IMDM, the four sera (Albumax II, BSA, FBS and NCS) were compared to the serum free culture (No serum). The three concentrations of each serum $(0.5 \%, 1 \%$ and $1.5 \%$ for Albumax II and BSA; 5\%, $10 \%$ and $15 \%$ for FBS and NCS) were labelled using the three ordinal levels: low, medium and high concentration; they were also compared to the serum-free culture. Interaction factors were created between explanatory variables and added to the models. The prediction of the motility by the protein concentration was poor, and there was a non-statistical difference between different concentrations of protein as will be discussed latter. Based on experimental observations, interactions were expected between the other three variables. Therefore, two ways and three ways interaction terms were created between those three experimental parameters: the presence of feeder cells, the culture medium used in reference to RPMI1640 and the type of protein supplement. 
The passage of the L. loa larvae from the third (L3) to the fourth (L4) stages was further considered the second target product profile in assessing the suitability of the culture systems tested. For each of the 78 culture systems designed and evaluated, the moulting rate (percentage of moulted worms) as well as the timeframe was computed.

\section{Results}

Evaluation of the effect of each basic culture medium on the viability of $L$. loa $\mathrm{L} 3$ and $\mathrm{mf}$

The $\mathrm{T}_{90}$ values of the parasite motility in different basic media were evaluated and results are presented in Fig. 1 and the statistical report in Table 1 . The values of $\mathrm{T}_{90}$ ranged from 3.0 day to 6.5 days for L3. In the absence of protein supplement and feeder cells, there were significant difference between the $\mathrm{T}_{90}$ value of the 3 media vis a vis the L3 $\left(\chi^{2}=38.793, d f=2, P<0.0001\right)$ and $\mathrm{mfs}\left(\chi^{2}=38.793\right.$, $d f=2, P<0.0001)$. Pairwise comparison indicated that L3 survived longer particularly in IMDM compared to DMEM $(P<0.0001)$ and RPMI $(P<0.0001)$, whereas $\mathrm{mf}$ hardly exceeded 3 days survival, irrespective of the culture medium tested in absence of supplements. However, $\mathrm{mf}$ survival time was significantly higher in DMEM than in RPMI $(P<0.0001)$ or IMDM $(P=0.0010)$.
Evaluation of the effect of serum/protein supplementation on the viability of $L$. loa larvae and microfilariae in culture

Figure 2 and Fig. 3 show the effect of serum/protein supplements in various basic media with regards to the mean values of $\mathrm{T}_{90}$ of $L$. loa $\mathrm{L} 3$ and $\mathrm{mf}$, respectively.

\section{Effect of serum/protein on the viability of $L$. loa larvae AlbuMax ${ }^{\circledR}$ II}

Generally, the supplementation of DMEM and IMDM with AlbuMax ${ }^{\circ}$ II promoted the viability of larvae, increasing $\mathrm{T}_{90}$ by $1.5-2.5$-fold. RPMI supplemented with AlbuMax ${ }^{\circ}$ II inhibited the larvae viability $\left(\mathrm{T}_{90}<1\right.$ day, Fig. 2a).

\section{Fetal bovine serum (FBS)}

This serum could support the viability of larvae for up to 8.7 days when IMDM was supplemented with $10 \%$ FBS. $\mathrm{T}_{90}>5$ days was observed in all concentrations of FBS except in the RPMI supplement medium (Fig. 2b).

\section{Bovine serum albumin (BSA)}

All media supplemented with BSA also improved larvae viability with $\mathrm{T}_{90} \geq 5$ days, except for DMEM supplemented with $1 \%$ BSA and all concentrations of BSA with RPMI (Fig. 2c).

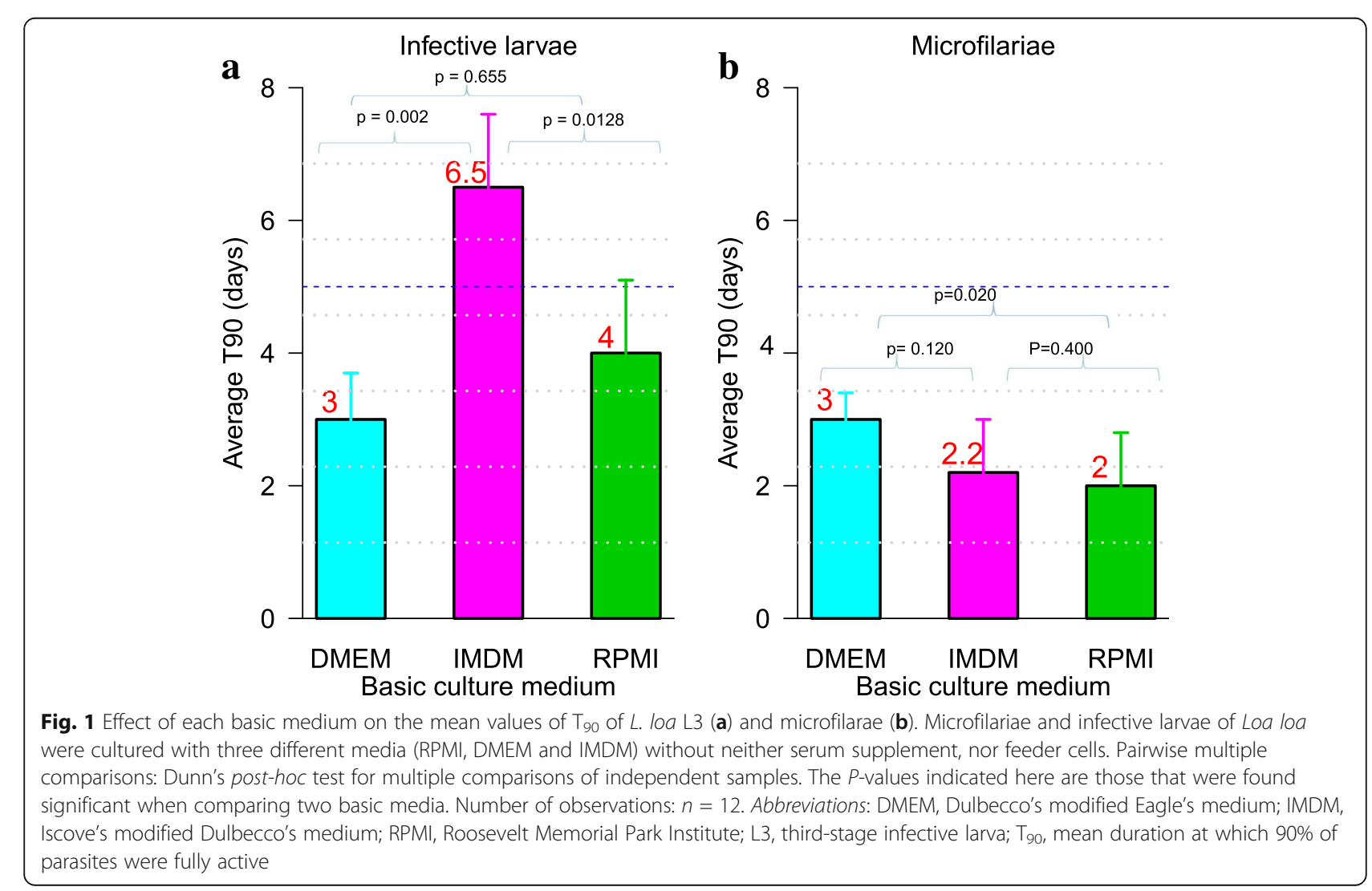


Table 1 Statistical report on the effect of serum/protein concentration in various culture systems with regards to the mean values of $T_{90}$ of $L$. loa microfilariae and L3

\begin{tabular}{|c|c|c|c|c|c|c|}
\hline Parasite & Feeder layer & Medium & Protein & Kruskal-Wallis $X^{2}$ & $d f$ & $P$-value \\
\hline \multirow[t]{24}{*}{ Loa loa mf } & \multirow[t]{12}{*}{ No } & \multirow[t]{4}{*}{ DMEM } & Albumax & 4.2585 & 3 & 0.2349 \\
\hline & & & BSA & 9.1681 & 3 & 0.0271 \\
\hline & & & FBS & 9.6542 & 3 & 0.0218 \\
\hline & & & NCS & 9.5639 & 3 & 0.0227 \\
\hline & & \multirow[t]{4}{*}{ IMDM } & Albumax & 16.1960 & 3 & 0.0010 \\
\hline & & & BSA & 22.8860 & 3 & $<0.0001$ \\
\hline & & & FBS & 19.1060 & 3 & 0.0003 \\
\hline & & & NCS & 23.1030 & 3 & $<0.0001$ \\
\hline & & \multirow[t]{4}{*}{ RPMI } & Albumax & 20.5860 & 3 & 0.0001 \\
\hline & & & BSA & 17.1480 & 3 & 0.0007 \\
\hline & & & FBS & 7.5795 & 3 & 0.0556 \\
\hline & & & NCS & 11.3590 & 3 & 0.0099 \\
\hline & \multirow[t]{12}{*}{ LLC-MK2 } & \multirow[t]{4}{*}{ DMEM } & Albumax & 6.9561 & 3 & 0.0733 \\
\hline & & & BSA & 6.1987 & 3 & 0.1023 \\
\hline & & & FBS & 4.9629 & 3 & 0.1745 \\
\hline & & & NCS & 6.1198 & 3 & 0.1059 \\
\hline & & \multirow[t]{4}{*}{ IMDM } & Albumax & 0.7759 & 3 & 0.8552 \\
\hline & & & BSA & 1.7466 & 3 & 0.6266 \\
\hline & & & FBS & 3.0427 & 3 & 0.3851 \\
\hline & & & NCS & 0.8119 & 3 & 0.8466 \\
\hline & & \multirow[t]{4}{*}{ RPMI } & Albumax & 16.8520 & 3 & 0.0008 \\
\hline & & & BSA & 14.6670 & 3 & 0.0021 \\
\hline & & & FBS & 0.3286 & 3 & 0.9546 \\
\hline & & & NCS & 2.3611 & 3 & 0.5009 \\
\hline \multirow[t]{19}{*}{ Loa loa L3 } & \multirow[t]{12}{*}{ No } & \multirow[t]{4}{*}{ DMEM } & Albumax & 7.0250 & 3 & 0.0711 \\
\hline & & & BSA & 8.3441 & 3 & 0.0394 \\
\hline & & & FBS & 8.1322 & 3 & 0.0434 \\
\hline & & & NCS & 6.0725 & 3 & 0.1081 \\
\hline & & \multirow[t]{4}{*}{ IMDM } & Albumax & 1.7999 & 3 & 0.6150 \\
\hline & & & BSA & 1.8722 & 3 & 0.5993 \\
\hline & & & FBS & 3.8436 & 3 & 0.2789 \\
\hline & & & NCS & 9.6063 & 3 & 0.0222 \\
\hline & & \multirow[t]{4}{*}{ RPMI } & Albumax & 8.4292 & 3 & 0.0379 \\
\hline & & & BSA & 4.2135 & 3 & 0.2393 \\
\hline & & & FBS & 6.5292 & 3 & 0.0885 \\
\hline & & & NCS & 1.4905 & 3 & 0.6845 \\
\hline & \multirow[t]{7}{*}{ LLC-MK2 } & \multirow[t]{4}{*}{ DMEM } & Albumax & 1.8177 & 3 & 0.6111 \\
\hline & & & BSA & 1.3618 & 3 & 0.7145 \\
\hline & & & FBS & 5.8987 & 3 & 0.1166 \\
\hline & & & NCS & 1.6916 & 3 & 0.6388 \\
\hline & & \multirow[t]{3}{*}{ IMDM } & Albumax & 16.0890 & 3 & 0.0011 \\
\hline & & & BSA & 5.2627 & 3 & 0.1535 \\
\hline & & & FBS & 2.1496 & 3 & 0.5419 \\
\hline
\end{tabular}


Table 1 Statistical report on the effect of serum/protein concentration in various culture systems with regards to the mean values of $T_{90}$ of L. loa microfilariae and L3 (Continued)

\begin{tabular}{|c|c|c|c|c|c|c|}
\hline Parasite & Feeder layer & Medium & Protein & Kruskal-Wallis $X^{2}$ & $d f$ & $P$-value \\
\hline & & & NCS & 4.9566 & 3 & 0.1750 \\
\hline & & RPMI & Albumax & 6.2386 & 3 & 0.1006 \\
\hline & & & BSA & 5.5548 & 3 & 0.1354 \\
\hline & & & FBS & 4.0227 & 3 & 0.2590 \\
\hline & & & NCS & 5.6006 & 3 & 0.1327 \\
\hline
\end{tabular}

\section{Newborn calf serum (NCS)}

Considering media supplemented with NCS, only DMEM with $5 \%$ NCS, IMDM with 10/15\% NCS had $\mathrm{T}_{90}>5$ days (Fig. 2d). Considering the 5-day cut-off point for drug screening, up to twenty culture media formulated based on the two basic culture media (DMEM and IMDM) and the four serum/protein supplements can be exploited for Loa L3 in priority: DMEM with $0.5 \%$ AlbuMax ${ }^{\circ}$ II $\left(\mathrm{T}_{90}=5.5 \pm\right.$ 1.9), $1 \%$ AlbuMax ${ }^{\circ}$ II $\left(\mathrm{T}_{90}=6.6 \pm 2.4\right), 1.5 \%$ AlbuMax $^{\circ} \mathrm{II}$
$\left(\mathrm{T}_{90}=6 \pm 1.8\right), 0.5 \%$ BSA $\left(\mathrm{T}_{90}=7.2 \pm 0.3\right), 1.5 \%$ BSA $\left(\mathrm{T}_{90}=5 \pm 1.9\right), 5 \%$ FBS $\left(\mathrm{T}_{90}=6.3 \pm 2\right), 10 \%$ FBS $\left(\mathrm{T}_{90}=7.8\right.$ $\pm 2.2), 5 \%$ FBS $\left(\mathrm{T}_{90}=7.3 \pm 2.7\right), 5 \% \mathrm{NCS}\left(\mathrm{T}_{90}=6.4 \pm 2.5\right)$, and IMDM with $0.5 \%$ AlbuMax $^{\circ}$ II $\left(\mathrm{T}_{90}=8.5 \pm 3.8\right), 1 \%$ AlbuMax $^{\odot}$ II $\left(\mathrm{T}_{90}=8 \pm 2.5\right), 1.5 \%$ AlbuMax $^{\odot} \mathrm{II}\left(\mathrm{T}_{90}=6.8 \pm\right.$ 2.5), 0.5\% BSA ( $\left.\mathrm{T}_{90}=6.7 \pm 1.2\right), 1 \% \mathrm{BSA}\left(\mathrm{T}_{90}=6.2 \pm 1.5\right)$, $1.5 \%$ BSA $\left(\mathrm{T}_{90}=7 \pm 2.2\right), 5 \%$ FBS $\left(\mathrm{T}_{90}=7.1 \pm 3\right), 10 \%$ FBS $\left(\mathrm{T}_{90}=8.7 \pm 2.6\right), 15 \%$ FBS $\left(\mathrm{T}_{90}=7.7 \pm 3.1\right), 10 \%$ NCS $\left(\mathrm{T}_{90}=7.1 \pm 2.4\right), 15 \% \mathrm{NCS}\left(\mathrm{T}_{90}=8.1 \pm 2.9\right)$.

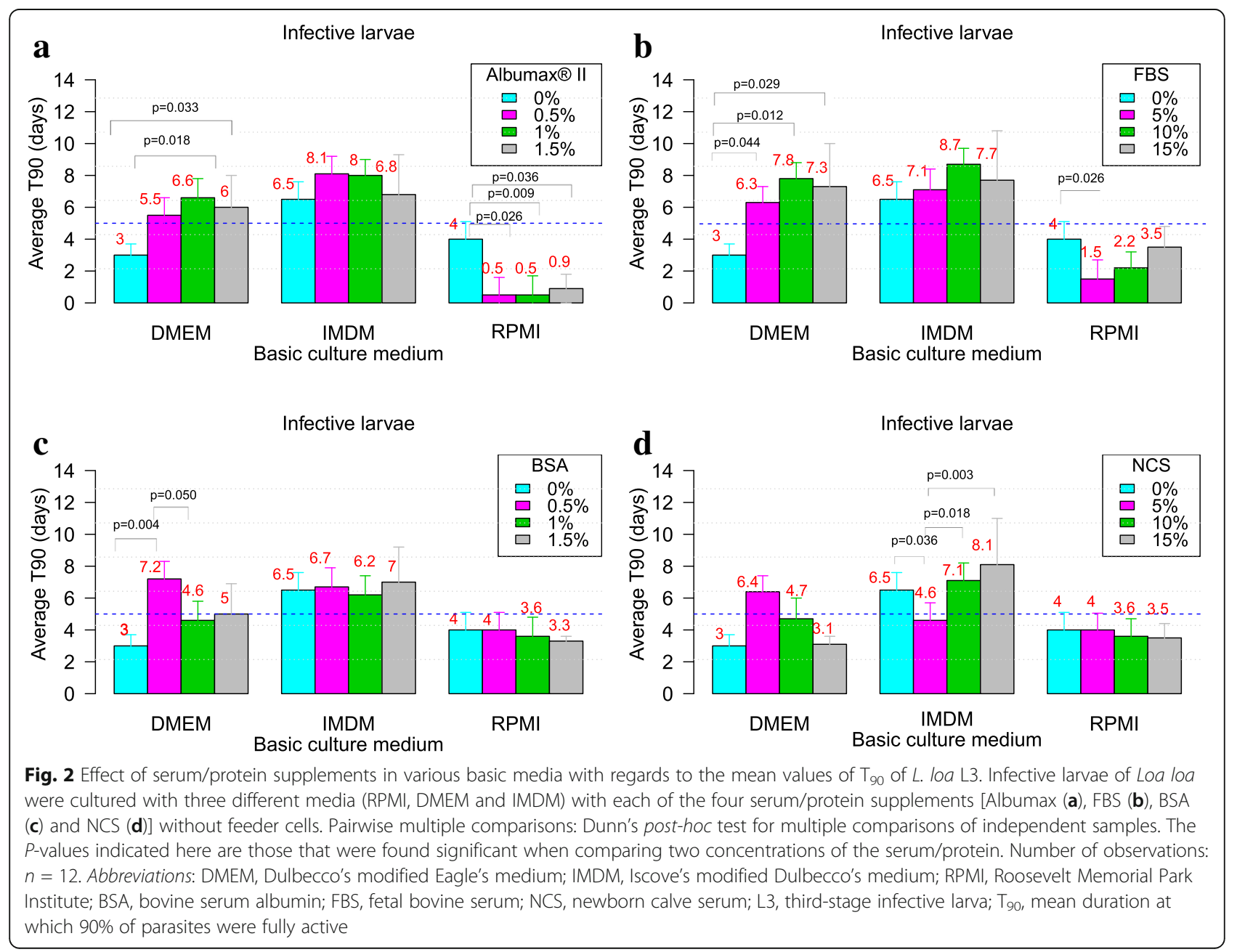




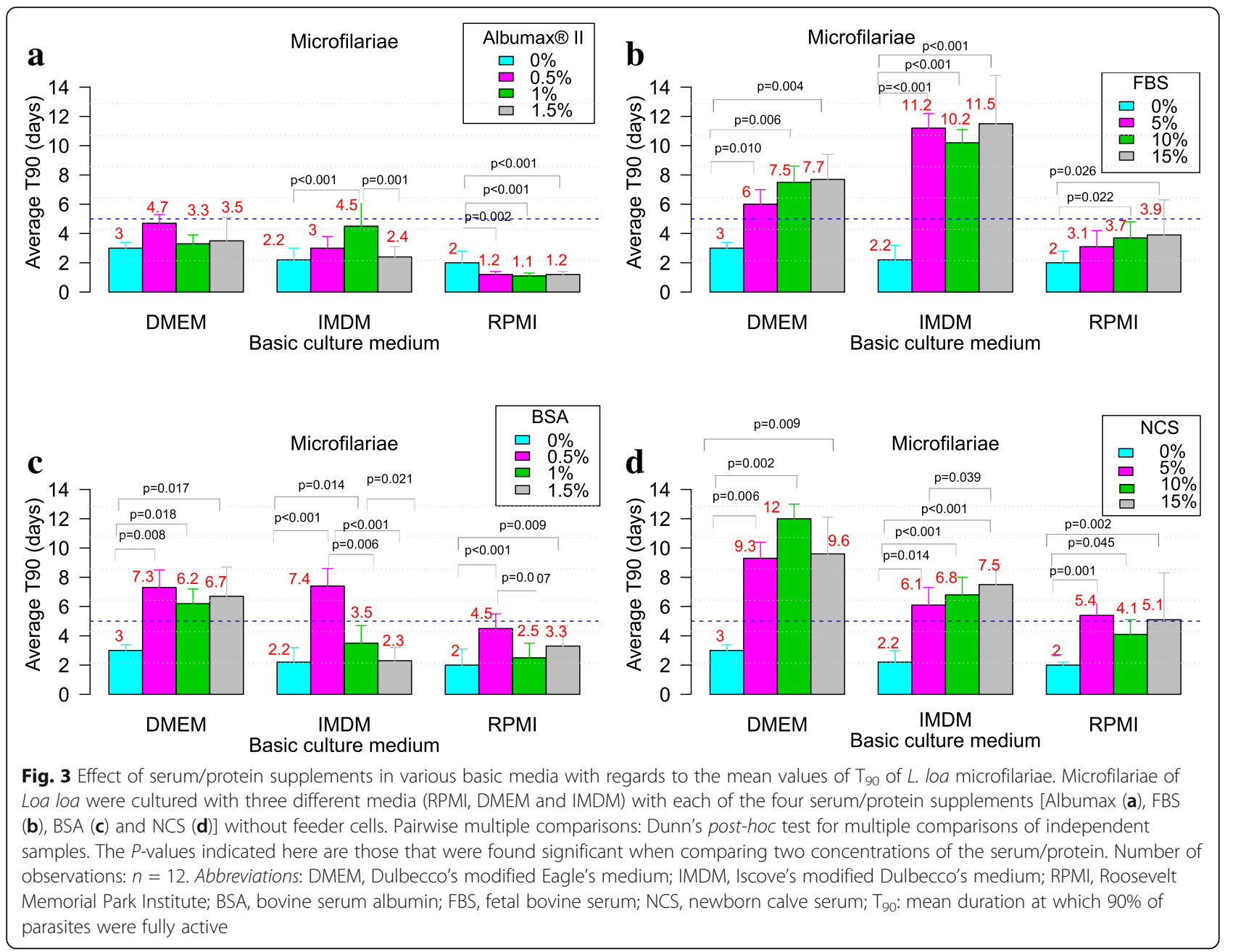

\section{Effect of serum/protein on the viability of $L$. loa microfilariae \\ AlbuMax ${ }^{\circledR}$ II}

All concentrations of AlbuMax II supplement improve the viability of $\mathrm{mf}$ regardless the basic medium except for RPMI. Although the improvement was noticeable, all $\mathrm{T}_{90}$ were less than 5 days as shown in Fig. $3 \mathrm{a}$.

\section{Fetal bovine serum (FBS)}

All concentrations of fetal bovine serum improved parasite viability but $\mathrm{T}_{90}>5$ days was reported only with FBS supplemented DMEM and IMDM (Fig. 3b).

\section{Bovine serum albumin (BSA)}

Generally, BSA boosted the microfilariae viability. The $\mathrm{T}_{90}$ values above 5 days were reported with all concentrations of BSA supplemented DMEM and IMDM $+0.5 \%$ BSA (Fig. 3c).

\section{Newborn calf serum (NCS)}

With respect to media supplemented with NCS, only RPMI supplemented with 10\% NCS could not sustain the L. loa $\mathrm{mf}$ for up to $\mathrm{T}_{90}=5$ days. Generally, NCS supplementation improved the L. loa mf viability by up to 4-fold as compared to basic medium without protein supplement (DMEM with $10 \% \mathrm{NCS}, \mathrm{T}_{90}=12 \pm 1$ days and DMEM only, $\mathrm{T}_{90}=3 \pm 0.4$ days), respectively (Fig. $3 \mathrm{~d}$ ).

With respect to Loa $\mathrm{mf}$, none of the media supplemented with AlbuMax ${ }^{\circ}$ II irrespective of the protein concentration could improve microfilaria viability for up to $\mathrm{T} 90 \geq 5$. Nevertheless, up to eighteen culture media formulations based on all three basic culture media and the four serum/protein supplements had interesting $\mathrm{T}_{90}$ values. These are DMEM with $0.5 \% \mathrm{BSA}\left(\mathrm{T}_{90}=7.3 \pm 1\right.$. 8), $1 \%$ BSA $\left(\mathrm{T}_{90}=6.2 \pm 1.4\right), 1.5 \%$ BSA $\left(\mathrm{T}_{90}=6.7 \pm 1.7\right)$, $5 \%$ FBS $\left(\mathrm{T}_{90}=6 \pm 3.1\right), 10 \%$ FBS $\left(\mathrm{T}_{90}=7.5 \pm 2.9\right), 15 \%$ FBS $\left(\mathrm{T}_{90}=7.7 \pm 1.7\right), 5 \% \operatorname{NCS}\left(\mathrm{T}_{90}=9.3 \pm 4.4\right), 10 \%$ $\operatorname{NCS}\left(\mathrm{T}_{90}=12 \pm 1\right), 15 \%$ NCS $\left(\mathrm{T}_{90}=9.6 \pm 2.5\right)$; IMDM with $0.5 \%$ BSA $\left(\mathrm{T}_{90}=7.4 \pm 3.1\right), 5 \% \mathrm{FBS}\left(\mathrm{T}_{90}=11.2 \pm 2\right.$. 
6), $10 \%$ FBS $\left(\mathrm{T}_{90}=10.2 \pm 1.9\right), 15 \%$ FBS $\left(\mathrm{T}_{90}=11.5 \pm 3\right.$. 3), $5 \% \operatorname{NCS}\left(\mathrm{T}_{90}=6.1 \pm 1.2\right), 10 \% \mathrm{NCS}\left(\mathrm{T}_{90}=6.8 \pm 1.2\right)$ , $15 \%$ NCS $\left(\mathrm{T}_{90}=7.5 \pm 1.4\right)$ and RPMI with $5 \%$ NCS $\left(\mathrm{T}_{90}=5.4 \pm 4.9\right), 15 \% \mathrm{NCS}\left(\mathrm{T}_{90}=5.1 \pm 3.2\right)$.

\section{Assessment of the importance of monkey kidney cells as feeder layer}

The findings on the effect of the monkey kidney epithelial cells as feeder on the survival of the L. loa L3 and $\mathrm{mf}$ are summarized in Fig. 4 and Fig. 5, respectively and the summary of the statistical report is presented in Table 2. Co-culture of L3 or $\mathrm{mf}$ with LLC-MK2 cells significantly improved the longevity of parasites culture with each basic media in the absence of serum/protein supplements. With respect to Loa L3, only DMEM with LLC-MK2 (No serum/protein supplement) enhanced viability by 3 -fold $(9.8 \pm 2.7)$, as compared to DMEM without serum ( $\mathrm{T}_{90}$ of $\left.3 \pm 1\right)$. It was not the case regarding IMDM with LLC-MK2 $\left(\mathrm{T}_{90}=5.8\right.$ $\pm 2.4)$ and RPMI with LLC-MK2 $\left(\mathrm{T}_{90}=5.2 \pm 2\right)$. When combining feeder cells with serum/protein supplements, the parasite survival and motility were even more increased, with highest $\mathrm{T}_{90}$ per basic culture medium varying from 10.0 (5\% FBS in IMDM) to 17.8 days ( $5 \%$ NCS in DMEM).

Co-culture of microfilariae with feeder cells increased $\mathrm{T}_{90}$ values up to 7 -fold (22.5 \pm 2.7 days). All serum/protein supplemented systems in co-culture were suitable ( $\mathrm{T}_{90}$ significantly greater than 5 days) with DMEM and IMDM; but RPMI supplemented with AlbuMax II remained sub-standard despite the presence of LLCMK2 feeder layer. Microfilariae co-cultured on LLCMK2 in basic culture media alone $\mathrm{T}_{90}$ values (DMEM $\mathrm{T}_{90}=19.5 \pm 2.8 ; \mathrm{IMDM} \mathrm{T}_{90}=19.5 \pm 5.2 ;$ and RPMI $\mathrm{T}_{90}$ $=16.4 \pm 1.7$ ) were not statistically different from their best protein/serum supplemented counterpart $(0.5 \%$ BSA supplemented DMEM on LLC-MK2 $\mathrm{T}_{90}=22.5 \pm$ 2.7; $5 \%$ NCS supplemented IMDM on LLC-MK2 $\mathrm{T}_{90}=$ $20.3 \pm 4.9$; and $1 \%$ BSA supplemented RPMI on LLCMK2 $\mathrm{T}_{90}=20.8 \pm 1.6$ ). The ranking of the observed $\mathrm{T}_{90}$ values of the various tested systems are summarised in Additional file 2: Table S2.

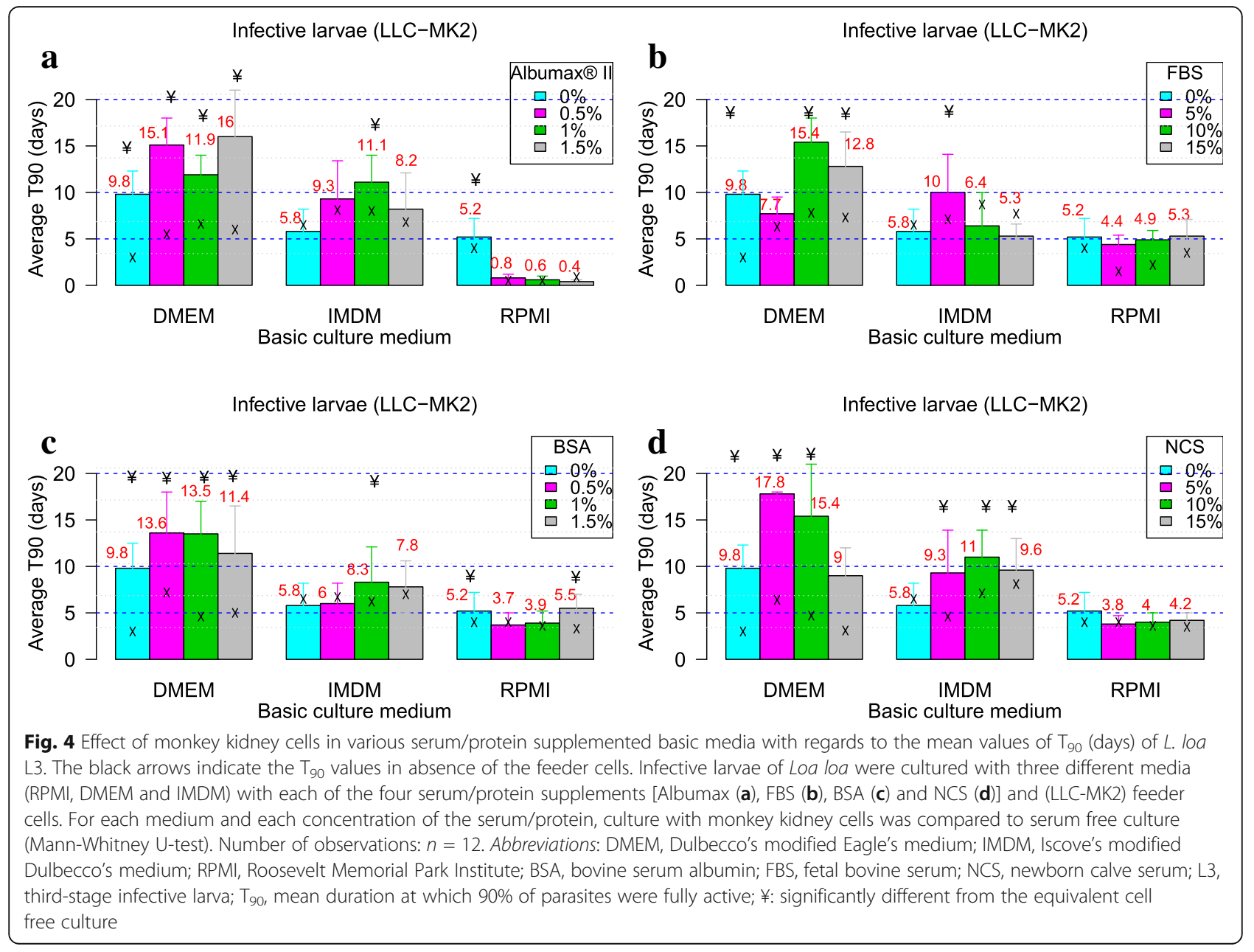




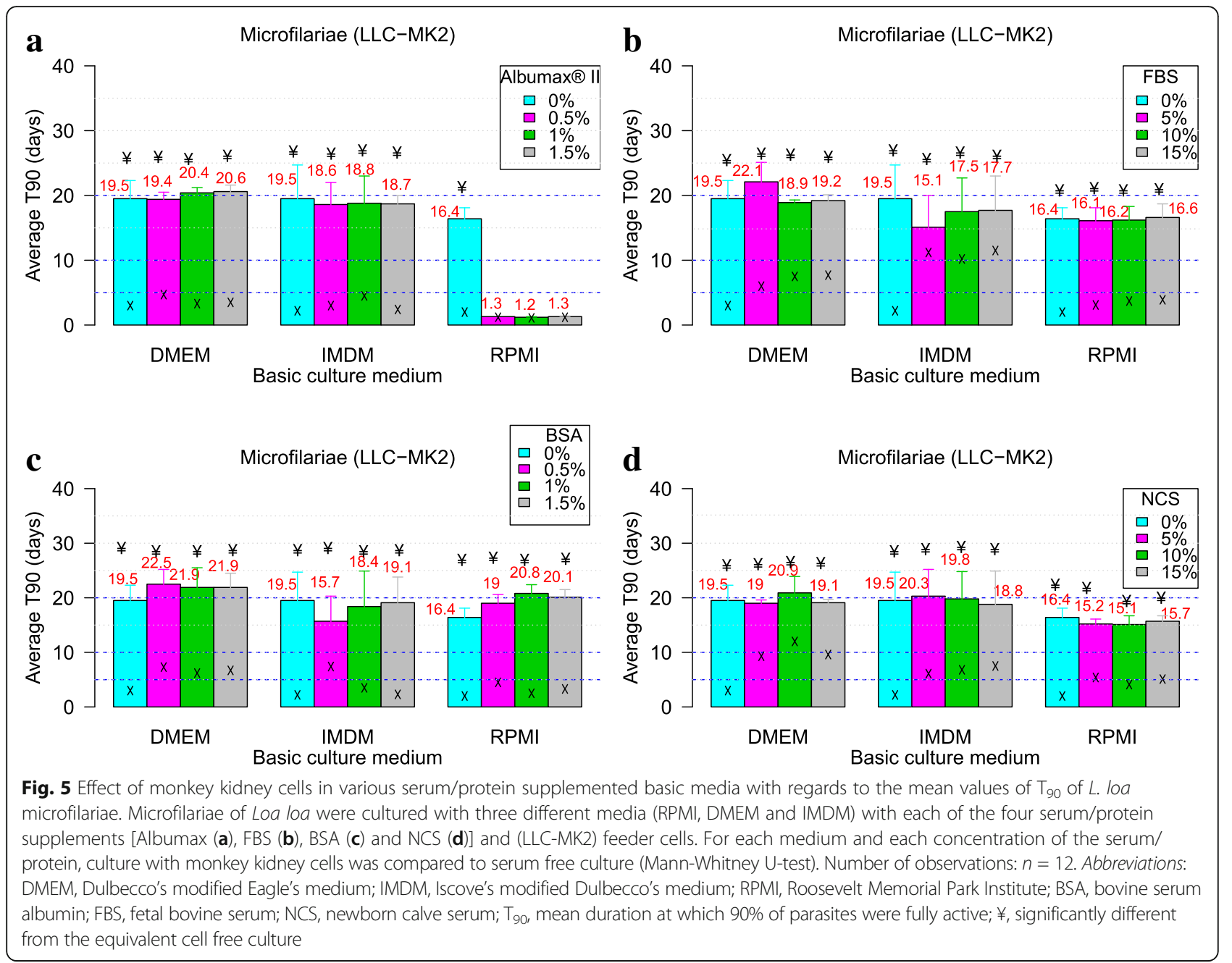

Effect of the different culture systems on the moulting from L3 to the fourth-stage larvae of L. loa

Moulting was observed following $L$. loa L3 culture, but its occurrence varied widely with culture conditions with values up to $70.37 \%$ (in 1\% BSA supplemented DMEM in co-culture with LLC-MK2). Variation in moulting rate are presented in Figs. 6, 7 and 8, Additional file 3: Table S3, with an illustration in Fig. 9. The proportion of moulting recorded with RPMI was below 25\%. This contrasted with DMEM and IMDM where significant moulting rates were noted, both in cell-free and coculture of L3 with LLC-MK2. Apart from the isolated case of IMDM with up to $27.27 \%$ (24 moulted worms out of a total of 88 ), serum/protein supplementation was found indispensable for the transition from L3 to L4 in vitro. The higher moulting rates were generally observed with DMEM, compared to IMDM. The highest moulting rate was observed in protein and feeder layer supplemented DMEM as illustrated in Fig. 6. Loa loa L3 moulting began on day 9 and observation was continued until day 29, supplementation with BSA scored highest moulting rates, with 57.32, 70.37 and 58.62\% larvae moulted in $0.5,1$ and $1.5 \%$ BSA supplement, respectively.

\section{Linear regression analysis of different factors that influence the in vitro maintenance of $L$. loa microfilariae and L3}

Bivariate analysis indicated strong association between motility and incubation time (Spearman's rho $=-0.674$, $P<0.001)$. This was the first to be introduced in the single linear regression analysis $\left(R^{2}=0.452\right)$, and the remaining variables were successively added to construct the final GLM. Before interaction terms were introduced in the models, the important factors that contributed to the improvement of worm motility were identified separately based on their standardized coefficient (Fig. 10). For Loa loa $\mathrm{mf}$, these factors included feeder cells $(\beta=0.490)$, both $\operatorname{IMDM}(\beta=0.256)$ and DMEM $(\beta=0.198)$ media and the protein supplements NCS $(\beta=0.052)$ and FBS $(\beta=0.022)$; for Loa loa L3, in addition to feeder cells $(\beta=0.259)$ and both $\operatorname{IMDM}(\beta=0.401)$ and $\operatorname{DMEM}(\beta=0.385)$ 
Table 2 Summary statistics on the effect of the addition of monkey kidney cells in various serum/protein supplemented basic media with regards to the mean values of $T_{90}$ of $L$. loa $\mathrm{L} 3$ and microfilariae

\begin{tabular}{|c|c|c|c|c|c|c|}
\hline \multirow[t]{2}{*}{ Medium } & \multirow{2}{*}{$\begin{array}{l}\text { Serum/ } \\
\text { Protein }\end{array}$} & \multirow{2}{*}{$\begin{array}{l}\text { Concentration } \\
\text { (\%) }\end{array}$} & \multicolumn{2}{|l|}{ Loa loa L3 } & \multicolumn{2}{|l|}{ Loa loa mf } \\
\hline & & & Mann-Whitney U & $P$-value & Mann-Whitney U & $P$-value \\
\hline \multirow[t]{13}{*}{ DMEM } & No serum & & 32 & 0.0084 & 24 & 0.0139 \\
\hline & \multirow[t]{3}{*}{ Albumax } & 0.5 & 16 & 0.0452 & 12 & 0.0471 \\
\hline & & 1 & 16 & 0.0476 & 35 & 0.0025 \\
\hline & & 1.5 & 21 & 0.0467 & 16 & 0.0286 \\
\hline & \multirow[t]{3}{*}{ BSA } & 0.5 & 15 & 0.0167 & 12 & 0.0471 \\
\hline & & 1 & 19 & 0.0171 & 48 & 0.0006 \\
\hline & & 1.5 & 14 & 0.0462 & 32 & 0.0040 \\
\hline & \multirow[t]{3}{*}{ FBS } & 5 & 6 & 0.5462 & 15 & 0.0357 \\
\hline & & 10 & 15 & 0.0167 & 24 & 0.0095 \\
\hline & & 15 & 12 & 0.0448 & 35 & 0.0025 \\
\hline & \multirow[t]{3}{*}{ NCS } & 5 & 15 & 0.0167 & 6 & 0.0200 \\
\hline & & 10 & 22 & 0.0381 & 20 & 0.0159 \\
\hline & & 15 & 24 & 0.0095 & 20 & 0.0158 \\
\hline \multirow[t]{13}{*}{ IMDM } & \multicolumn{2}{|l|}{ No serum } & 25 & 0.4945 & 56 & 0.0003 \\
\hline & \multirow[t]{3}{*}{ Albumax } & 0.5 & 20.5 & 0.7479 & 54 & 0.0004 \\
\hline & & 1 & 36 & 0.0137 & 80 & 0.0004 \\
\hline & & 1.5 & 21.5 & 0.9999 & 70 & 0.0001 \\
\hline & \multirow[t]{3}{*}{ BSA } & 0.5 & 14.5 & 0.6303 & 36 & 0.0069 \\
\hline & & 1 & 32 & 0.0345 & 96 & 0.0002 \\
\hline & & 1.5 & 25 & 0.9497 & 96 & 0.0002 \\
\hline & \multirow[t]{3}{*}{ FBS } & 5 & 26 & 0.024 & 18 & 0.0257 \\
\hline & & 10 & 12 & 0.1419 & 91 & 0.0003 \\
\hline & & 15 & 11 & 0.1079 & 72 & 0.0490 \\
\hline & \multirow[t]{3}{*}{ NCS } & 5 & 31 & 0.0411 & 54 & 0.0004 \\
\hline & & 10 & 38 & 0.0813 & 96 & $<0.0001$ \\
\hline & & 15 & 31 & 0.0414 & 96 & $<0.0001$ \\
\hline \multirow[t]{13}{*}{ RPMI } & No serum & & 26 & 0.0109 & 98 & 0.0003 \\
\hline & \multirow[t]{3}{*}{ Albumax } & 0.5 & 14 & 0.2413 & 32.5 & 0.3170 \\
\hline & & 1 & 20 & 0.1087 & 83 & 0.0685 \\
\hline & & 1.5 & 10 & 0.7483 & 86 & 0.1764 \\
\hline & \multirow[t]{3}{*}{ BSA } & 0.5 & 6 & 0.9999 & 40 & 0.002 \\
\hline & & 1 & 9 & 0.4000 & 77 & $<0.0001$ \\
\hline & & 1.5 & 17 & 0.0111 & 77 & 0.0006 \\
\hline & \multirow[t]{3}{*}{ FBS } & 5 & 15 & 0.3571 & 35 & 0.0057 \\
\hline & & 10 & 16 & 0.2857 & 56 & $<0.0001$ \\
\hline & & 15 & 16 & 0.1905 & 91 & 0.0004 \\
\hline & \multirow[t]{3}{*}{ NCS } & 5 & 6.5 & 0.9999 & 29 & 0.0282 \\
\hline & & 10 & 9 & 0.4000 & 88 & 0.0003 \\
\hline & & 15 & 13 & 0.2000 & 88 & 0.0003 \\
\hline
\end{tabular}

media, the proteins supplement BSA $(\beta=0.029)$ were found important for the maintenance of the worm motility.
From the built models, the important variables required to meet the threshold of $\mathrm{T}_{90}$ are as followed and classified with respect to their importance. Feeder cells 


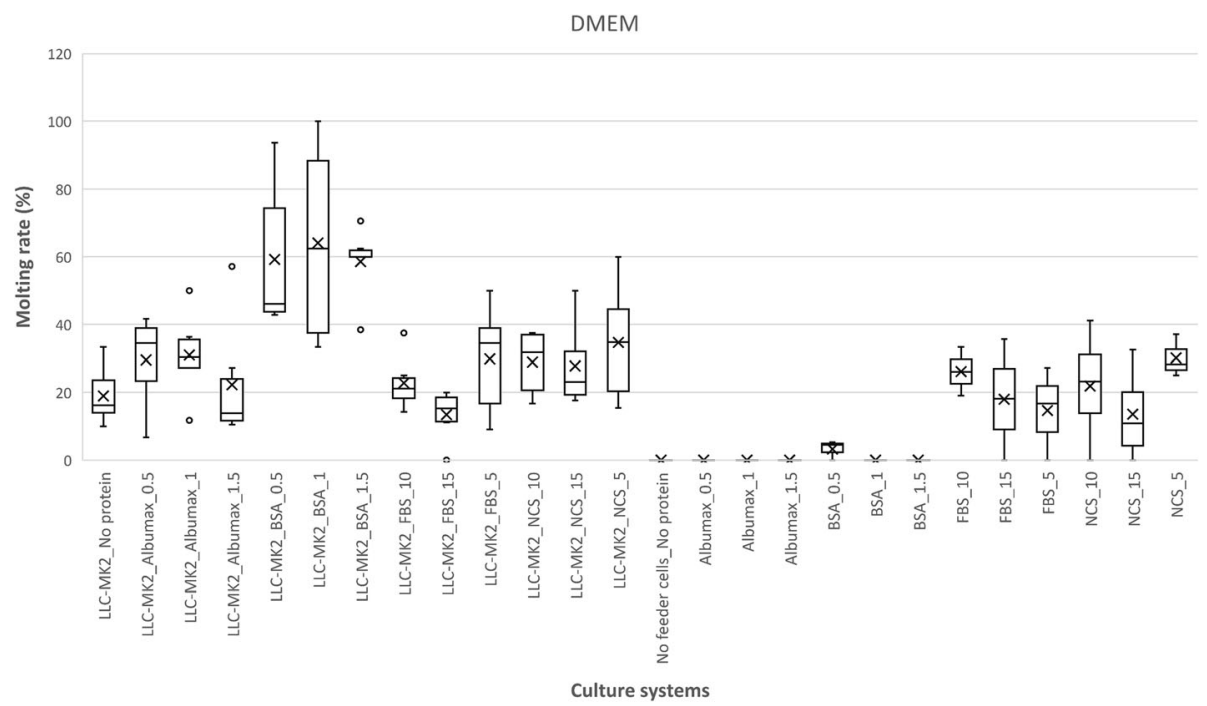

Fig. 6 Effects of serum/protein supplements at different concentrations added to DMEM basic medium with or without feeder layer on the moulting L. loa infective larvae in culture. Number of observations: $n=12$. Abbreviation: DMEM: Dulbecco's modified Eagle's medium

were found as the most important. In combination to DMEM (DMEM-LLCMK2), the unstandardized coefficient decreased although the interaction was the best among others. In addition, the combination of three variables (feeder layer-basic culture medium-protein/serum supplement) was not mandatory as the interaction LLCMK2-Albumax instead weakened the model with a negative coefficient.

The model was diagnosed by assessing the assumptions of normal distribution and homoscedasticity. The histogram of the residuals (errors) in the model was used to check if they are normally distributed (Additional file 4: Figure S1). Although not perfect, the frequency distribution of the residuals has a shape close to that of the normal Gauss curve, indicating evidence of normal distribution. Additionally, P-P plot was used for further check (Additional file 5: Figure S2). Here, the expected and observed cumulative probabilities were closed suggesting that the assumption of normal distribution of the residual was far to be not violated. The scatterplot of standardized residuals against standardized predicted values were used to assess the assumption of homoscedasticity (Additional file 6: Figure S3). The variance of residuals were random distributed indicating that the assumption of homoscedasticity was likely to be safe.

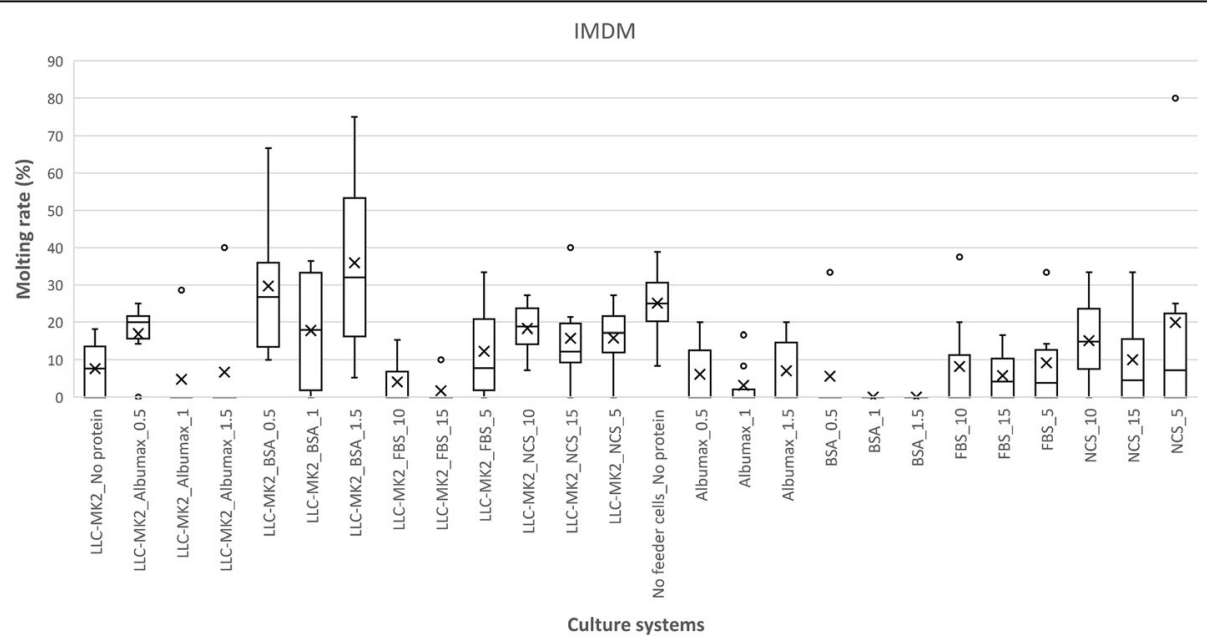

Fig. 7 Effects of serum/protein supplements at different concentrations added to IMDM basic medium with or without feeder layer on the moulting L. loa infective larvae in culture. Number of observations: $n=12$. Abbreviation: IMDM: Iscove's modified Dulbecco's medium 


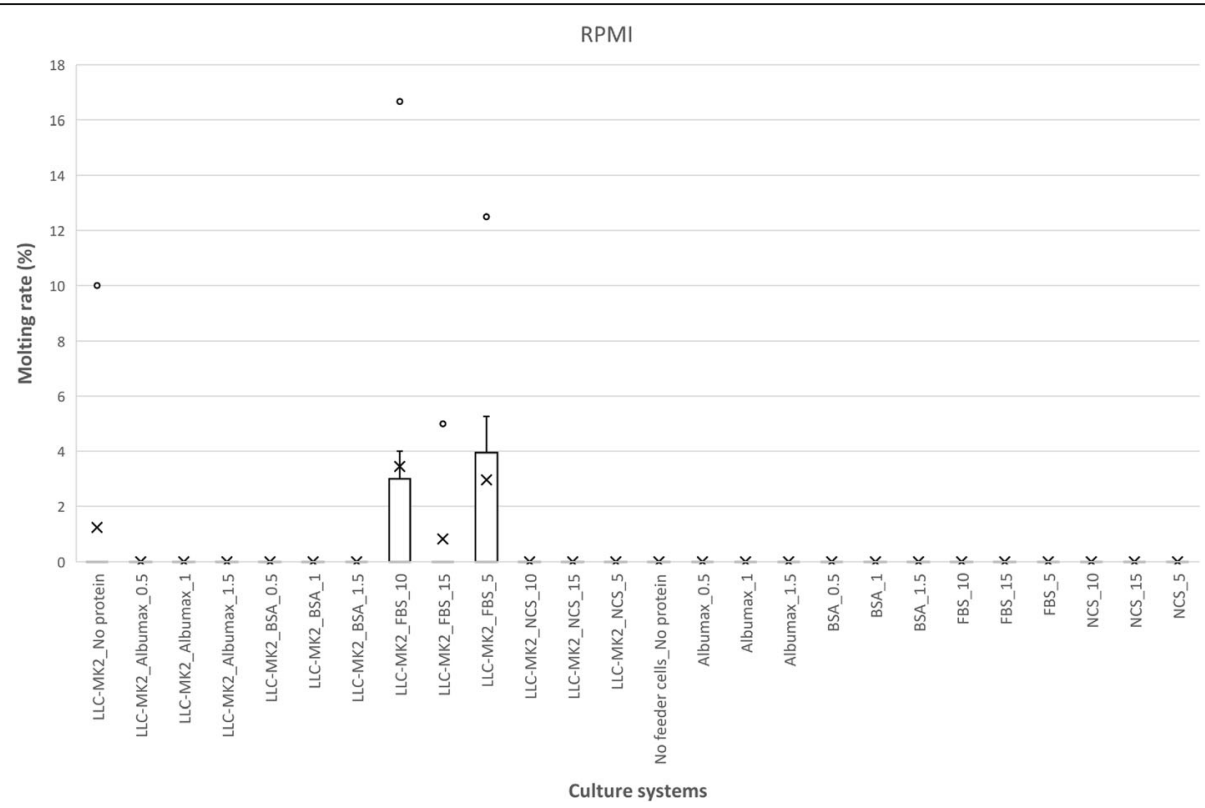

Fig. 8 Effects of serum/protein supplements at different concentrations added to RPMI basic medium with or without feeder layer on the moulting L. loa infective larvae in culture. Number of observations: $n=12$. Abbreviation: RPMI: Roosevelt Memorial Park Institute

\section{Discussion}

Drug discovery research for $L$. loa has so far attracted only very limited attention compared to other filarial diseases. Repurposing attempts have been conducted with existing drugs with only limited success. The effect of several antimalarial drugs (quinine, chloroquine, amodiaquine and artesunate) was investigated on loiasis in a randomized, placebo-controlled approach in central Cameroon [20]. This study recorded no significant change in parasite loads in any of the treatment groups. Another study tested different intermittent doses of albendazole on Loa loa microfilaraemia, the reduction in $\mathrm{mf}$ load obtained was insufficient to prevent the risk of severe adverse reactions during ivermectin mass drug administration in loiasis co-endemic areas [21]. These observations demonstrated that repurposing of existing antiparasitic therapies may not be a suitable approach to develop drugs with satisfactory therapeutic window. The traditional approach starting from standard in vitro discovery through preclinical and clinical testing necessitates in vitro maintenance of $L$. loa stages for a minimum duration required for drug screening. Herein we designed and tested the effect of varying 78 culture conditions on both L3 and $\mathrm{mf}$ viability starting with three basic culture media, four serum/protein supplements and one feeder cell. In general, L. loa L3 survived for longer periods than $\mathrm{mf}$ in the different basic culture media with neither protein nor feeder cell supplementation. For the maintenance of L3, IMDM exhibited the best performance, whereas on microfilariae, DMEM had the highest $\mathrm{T}_{90}$ though only three-day survival. Considering a minimum cut-off point of five-day maintenance of $90 \%$ highly active larvae or microfilariae for in vitro drug screening on $L$. loa microfilariae and infective
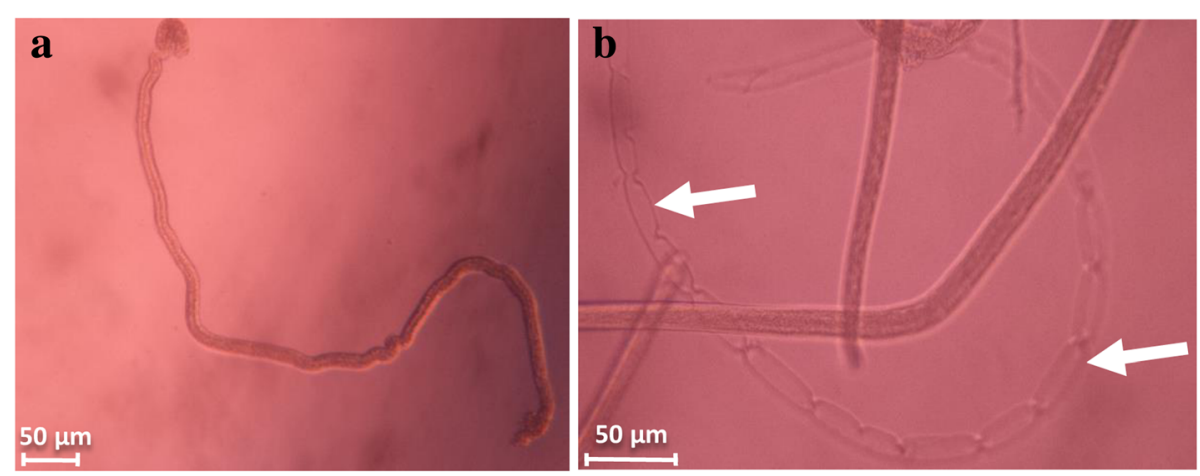

Fig. 9 Image of moulted worms observed under inverted microscope. a Fully moulted Loa L4 larva. b Cast cuticule from moulted Loa L3 (arrows) 


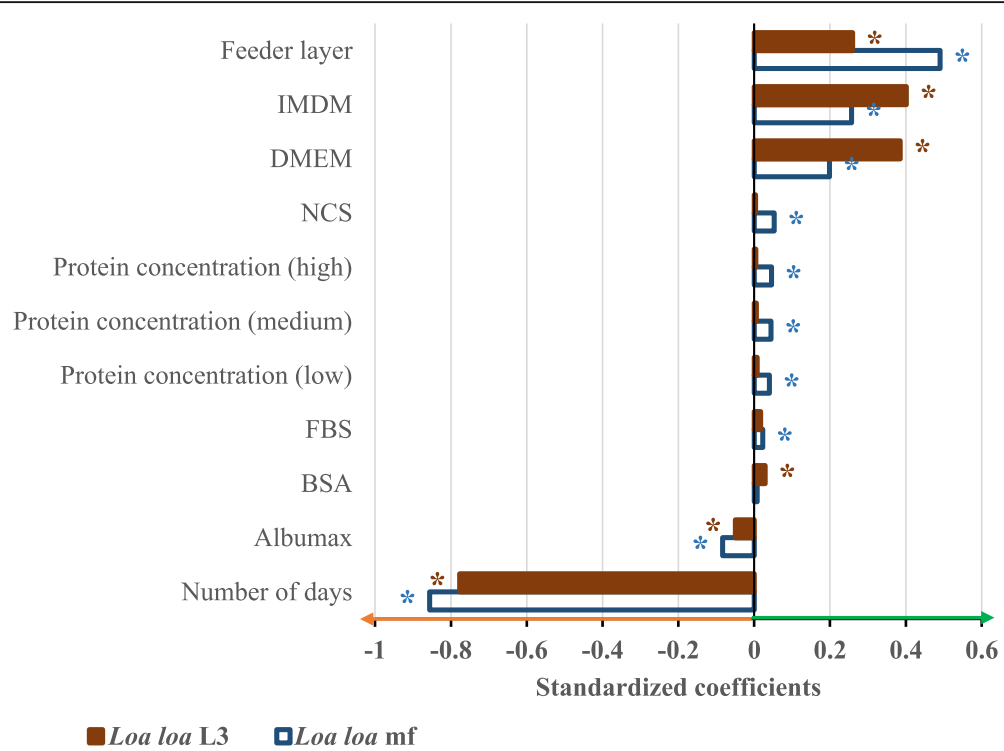

Fig. 10 Graphical representation of the standardized coefficients of the main effects of different factors on the predicted Loa loa microfilariae and L3 motility. Adjusted $R^{2}$ : L. loa mf $=0.709 ;$ L. loa L3 $=0.716$

larvae, IMDM was the only basic medium that could be employed as such without any need of protein supplement/feeder layer. However, none of the media would be suitable for in vitro investigations requiring longer periods of incubation.

Four different serum/protein supplements were therefore applied at increasing concentrations to the three basic culture media in order to improve their nutritional potencies for both $\mathrm{L} 3$ and $\mathrm{mf}$. The results obtained were highly diverse. In RPMI, serum/protein supplementation rather caused drop in $T_{90}$ which was more pronounced for AlbuMax II followed by FBS, NCS and BSA, in both L3 and mf. Consequently, none of the formulations based on RPMI supplemented with serum/protein (without feeder layer) was successful in keeping $\mathrm{mf}$ alive and active for more than five days. Mengome et al. [22] recently reported on screening of 12 methanolic extracts of nine traditional plant remedies employed in Gabon, on L. loa mf maintained in vitro using modified Eagle's medium supplemented with $10 \%$ foetal calf serum with five-day incubation time. Our findings showing an average $\mathrm{T}_{90}$ value of $7.5 \pm 2.9$ days and thus corroborate the data reported by these authors, confirming the suitability of the culture system employed.

A drastic increase in the survival time and viability of the L. loa $\mathrm{mf}$ was obtained with addition of LLC-MK2 cells as feeder layer, except for AlbuMax ${ }^{\circ}$ II in RPMI. The $\mathrm{T}_{90}$ values were extended for all culture formulations (except AlbuMax ${ }^{\circ}$ II in RPMI), even exceeding 20 days.

The hypothesis that LLC-MK2 cells alone can be enough to sustain the viability of the $L$. loa parasites in vitro was tested. In all the three basic culture media,
RPMI, DMEM and IMDM, without serum/protein supplement, parasites could still survive 15 days and beyond. Toback et al. [23] reported that monkey kidney cells during their growth in vitro produce growth factors such as the epidermal growth factor (EGF), interleukin growth factor (IGF) and transforming growth factor (TGF- $\beta$ ). Thus, these factors are possibly supportive of L. loa larval growth and/or survival, which facilitate their in vitro maintenance.

Culture systems capable of sustaining moulting of infective larvae present an additional advantage for in vitro investigations on the parasite, including both physiological studies and the exploration of drug targets. In addition to the survival of parasites, the effect of the different culture systems on the moulting of L3 was further examined. Maintenance and moulting of filariae larvae using different culture systems have been reported for Onchocerca spp. [24, 25], Wuchereria bancrofti [26-29] and Brugia malayi [30,31]. The present study is the first attempt to optimise such systems for $L$. loa larvae.

Of the total of 659 moulted worms observed, the distribution with respect to each medium was as followed: DMEM (70\%) followed by IMDM (29\%) and finally RPMI (1\%). The proportion of moulting observed in DMEM + LLC-MK2 varied with the nature of the serum/protein supplement. $62.44 \%(138 / 221)$ in BSA, $30.15 \%(79 / 262)$ in NCS, $24.52 \%(64 / 261)$ in AlbuMax II and 22.38\% (45/201) in FBS. The moulting rate in BSA was statistically different $(P<0.001)$ from the three other sera. With BSA supplementation, $1 \%$ proved to be optimum with a $70.37 \%$ moulting rate, compared with $1.5 \%$ and $0.5 \%$ with rates of 
$58.62 \%$ and $57.32 \%$, respectively. Although the role of albumin in the promotion of L. loa L3 moulting is still to be elucidated, Ishima et al. [32] reported on some beneficial effects from the interaction of albumin with other biological factors such as insulin, epidermal growth factor in the in vitro culture of mammalian cells, suggesting that this combination of BSA and LLC-MK2 as supplements provided optimal in vitro conditions for $L$. loa L3 moulting. Smith et al. [33] have developed a serum-free in vitro system for Brugia malayi third infective larvae, by supplementing RPMI 1640 with either arachidonic, linoleic or linolenic acids and this supported consistent and reproducible moulting to the fourth larval stage in the presence of a basidiomycetous yeast, Rhodotorula minuta. In serum-free cultures lacking $R$. minuta, L3 larvae survive for upward of two weeks, but did not moult. Smith \& Rajan [34] subsequently used this system to study the effect of tetracycline on three different species of filarial nematodes, Brugia malayi, Brugia pahangi and Dirofilaria immitis.

In summary, IMDM and DMEM were the two basic media found to be more suitable to culture L. loa L3 and $\mathrm{mf}$, respectively, for short incubation time (for up to 7 days); DMEM + 5\% NCS and IMDM + 10\% FBS are suitable to culture both $L$. loa $\mathrm{mf}$ and L3 for relatively long incubation time (for up to two weeks); DMEM + LLC-MK2 was suitable to culture $L$. loa $\mathrm{mf}$ for long incubation time while DMEM + $1 \%$ BSA + LLC-MK2 provided optimal moulting conditions for $L$. loa L3.

\section{Conclusions}

This study has demonstrated the effects of protein supplemented basic media in association with or without monkey kidney cells on the survivorship of $L$. loa microfilariae and on the survival and moulting of $L$. loa infective larvae. The findings from this work provide a range of culture requirements for the maintenance of $L$. loa, which are suitable for developing an effective platform for drug screening.

\section{Additional files}

Additional file 1: Table S1. Summary of the contribution of the main effects of various variables in the model. (DOCX $26 \mathrm{~kb}$ )

Additional file 2: Table S2. Ranking of the various experimental systems. (DOCX $26 \mathrm{~kb}$ )

Additional file 3: Table S3. Moulting rate (\%) of L. loa $\mathrm{L} 3$ in different in vitro culture systems. (DOCX $17 \mathrm{~kb}$ )

Additional file 4: Figure S1. Motility standardized residual histogram of the motility. (DOCX $41 \mathrm{~kb}$ )

Additional file 5: Figure S2. Gaussian regression P-P plot of predicted motility. (DOCX $27 \mathrm{~kb}$ )

Additional file 6: Figure S3. Scatterplot of standardized residuals against standardized predicted values. (DOCX $29 \mathrm{~kb}$ )

\section{Abbreviations}

APOC: African Programme for Onchocerciasis Control; BSA: bovine serum albumin; DMEM: Dulbecco's modified Eagle's medium; FBS: foetal bovine serum; IMDM: Iscove's modified Dulbecco's medium; LLC-MK2: Lewis lung carcinoma Monkey Kidney cell line 2; NCS: newborn calf serum;

NTDs: neglected tropical diseases; RPMI: Roswell Park Memorial Institute; $\mathrm{T}_{90}$ : mean duration (days) at which at least $90 \%$ of worms were fully active

\section{Acknowledgements}

The authors thank Mr Bernard Synkalbe and Mr Bruno Oben for their technical support.

\section{Funding}

This work was supported by a Bill and Melinda Gates Foundation Global Health Grand Challenges Explorations Grant awarded to JDT, SW and MJT (OPP10867).

\section{Authors' contributions}

ZD, FFF, NVTG and AJN contributed to the design of the study, carried out in vitro culture, data analysis and wrote the manuscript. JAOK, CNWP, PE and DTB produced parasitic materials and edited the manuscript. FRD, MJT and JDT assisted in study design and edited the manuscript. SW conceived and designed the study, and oversaw laboratory activities, data analysis and edited the manuscript. All authors read and approved the final manuscript.

\section{Competing interest}

The authors declare that they have no competing interests.

Ethics approval and consent to participate

Baboons (Papio anubis) used as parasite reservoir were handled according to international legislation and guidelines of the Cameroon National Veterinary Laboratory (LANVET, Ministry of Livestock, Fisheries and Animal Industry). The study design as well as different protocols was approved by the REFOTDE Institutional Animal Ethics Committee (RIAEC), with an ethical clearance obtained from this board, and the Cameroon National Ethics Committee (Ministry of Public Health). Handling of the animals and the investigations carried out were done strictly according to the international guidelines of rearing animals and using them in medical research under the official authorisation of the Ministry of Scientific Research in Cameroon (Research permit N ${ }^{\circ} 028 / \mathrm{MINRESI/B00/C00//C10/C12/2007).} \mathrm{The} \mathrm{manipulations} \mathrm{of} \mathrm{the}$ animals were done strictly according to the Animal Welfare Legislation and Policies, complied with the Animals (Scientific Procedures) Act 1986 (ASPA) and its associated codes of practice on animal housing and care [35]. Informed consent was obtained the human participant. Previous works that used the same procedures are found here $[13,15]$.

\section{Publisher's Note}

Springer Nature remains neutral with regard to jurisdictional claims in published maps and institutional affiliations.

\section{Author details}

${ }^{1}$ Research Foundation for Tropical Diseases and Environment (REFOTDE), South West Region, Buea, Cameroon. ${ }^{2}$ Biotechnology Unit, Faculty of Science, University of Buea, Buea, Cameroon. ${ }^{3}$ Parasites and Vectors Biology Research Unit (PAVBRU), Department of Microbiology and Parasitology, Faculty of Science, University of Buea, South West Region, Buea, Cameroon. ${ }^{4}$ Department of Parasitology, Liverpool School of Tropical Medicine, Liverpool, UK.

Received: 13 February 2018 Accepted: 16 April 2018

Published online: 02 May 2018

\section{References}

1. Padgett JJ, Jacobsen KH. Loiasis: African eye worm. Trans R Soc Trop Med Hyg. 2008;102:983-9.

2. Mongin A. Observations sur un ver trouvé sous la conjonctive à Maribarou, île Saint-Dominique. J Med Chir Pharm Paris. 1770;32:338-9.

3. Pinder M. Loa loa - a neglected filaria. Parasitol Today. 1988;4:279-84.

4. Poitevin R. Encéphalite filarienne à Loa loa. A propos d'un cas survenu après prise orale d'ivermectine. Thèse de Docorat en Medecine (MD). Université Paris XI. France. 1996; 
5. Chippaux JP, Boussinesq M, Gardon J, Gardon-Wendel N, Ernould JC. Severe adverse reaction risks during mass treatment with ivermectin in loiasisendemic areas. Parasitol Today. 1996;12:448-50.

6. Boussinesq M, Gardon J, Gardon-Wendel N, Kamgno J, Ngoumou P, Chippaux J-P. Three probable cases of Loa loa encephalopathy following ivermectin treatment for onchocerciasis. Am J Trop Med Hyg. 1998;58:461-9.

7. Gardon J, Gardon-Wendel N, Demanga N, Kamgno J, Chippaux JP, Boussinesq $M$. Serious reactions after mass treatment of onchocerciasis with ivermectin in an area endemic for Loa loa infection. Lancet. 1997;350(9070):18-22.

8. Lukiana T, Mandina M, Situakibanza NH, Mbula MM, Lepira BF, Odio WT, et al. A possible case of spontaneous Loa loa encephalopathy associated with a glomerulopathy. Filaria J. 2006;5:6.

9. Carme B, Boulesteix J, Boutes H, Puruehnce MF. Five cases of encephalitis during treatment of loiasis with diethylcarbamazine. Am J Trop Med Hyg. 1991:44:684-90

10. Centers for Diseases Control and Prevention (CDC). Parasites - Loiasis. http://www.cdc.gov/parasites/loiasis/treatment.html. Accessed Jan 2016.

11. Boussinesq M, Gardon J, Kamgno J, Pion S, Gardon-Wendel N, Chippaux J-P. Relationships between the prevalence and intensity of Loa loa infection in the Central Province of Cameroon. Ann Trop Med Parasitol. 2001;95:495-507.

12. Boussinesq M. Loiasis. Ann Trop Med Parasitol. 2006;100:715-731.

13. Wanji S, Eyong EE, Tendongfor N, Ngwa C, Esuka E, Kengne-Ouafo A, et al. Parasitological, hematological and biochemical characteristics of a model of hyper-microfilariaemic loiasis (Loa loa) in the baboon (Papio anubis). PLoS Negl Trop Dis. 2015;9:e0004202.

14. Halliday A, Guimaraes AF, Tyrer HE, Metuge HM, Patrick CN, Arnaud KO, et al. A murine macrofilaricide pre-clinical screening model for onchocerciasis and lymphatic filariasis. Parasit Vectors. 2014;7:472.

15. Tendongfor N, Wanji S, Ngwa JC, Esum ME, Specht S, Enyong P, et al. The human parasite Loa loa in cytokine and cytokine receptor gene knock out BALB/C mice: survival, development and localization. Parasit Vectors. 2012;5:43.

16. Wanji S, Eyong E-EJ, Tendongfor N, Ngwa CJ, Esuka EN, Kengne-Ouafo AJ, et al. Ivermectin treatment of Loa loa hyper-microfilaraemic baboons (Papio anubis): assessment of microfilarial load reduction, haematological and biochemical parameters and histopathological changes following treatment. PLoS Negl Trop Dis. 2017;11:e0005576.

17. Van Hoegaerden M, Ivanoff B. A rapid, simple method for isolation of viable microfilariae. Am J Trop Med Hyg. 1986;35:148-51.

18. O'Neill M, Geary JF, Agnew DW, Mackenzie CD, Geary TG. In vitro flubendazole-induced damage to vital tissues in adult females of the filarial nematode Brugia malayi. Int J Parasitol Drugs Drug Resist. 2015;5:135-40.

19. Njouendou AJ, Ritter M, Ndongmo WPC, Kien CA, Narcisse GTV, Fombad FF, et al. Successful long-term maintenance of Mansonella perstans in an in vitro culture system. Parasit Vectors. 2017;10:563.

20. Kamgno J, Djomo PN, Pion SD, Thylefors B, Boussinesq M. A controlled trial to assess the effect of quinine, chloroquine, amodiaquine, and artesunate on Loa loa microfilaremia. Am J Trop Med Hyg. 2010;82:379-85.

21. Kamgno J, Nguipdop-Djomo P, Gounoue R, Tejiokem M, Kuesel AC. Effect of two or six doses $800 \mathrm{mg}$ of albendazole every two months on Loa loa microfilaraemia: a double blind, randomized, placebo-controlled trial. PLoS Negl Trop Dis. 2016;10:e0004492.

22. Mengome LE, Akue JP, Souza A, Feuya Tchoua GR, Nsi Emvo E. In vitro activities of plant extracts on human Loa loa isolates and cytotoxicity for eukaryotic cells. Parasitol Res. 2010;107:643-50

23. Toback FG, Walsh-Reitz MM, Mendley SR, Kartha S. Kidney epithelial cells release growth factors in response to extracellular signals. Pediatr Nephrol. 1990;4:363-71

24. Lok JB, Pollack RJ, Cupp EW, Bernardo MJ, Donnelly JJ, Albiez EJ. Development of Onchocerca lienalis and O. volvulus from the third to fourth larval stage in vitro. Tropenmed Parasitol. 1984;35:209-11.

25. Townson S, Tagboto SK. In vitro cultivation and development of Onchocerca volvulus and Onchocerca lienalis microfilariae. Am J Trop Med Hyg. 1996;54:32-7.

26. Franke $E D$, Riberu W, Wiady I. In vitro cultivation of third-stage larvae of Wuchereria bancrofti to the fourth stage. Am J Trop Med Hyg. 1987;37:370-5.

27. Neves JM, Nardi NB, Andrade L, Dreyer G. In vitro differentiation of Wuchereria bancrofti (Filariidae). Braz J Med Biol Res. 1991;24:1011-6.

28. Zaraspe $\mathrm{G}$, Cross JH. Attempt to culture Wuchereria bancrofti in vitro. Southeast Asian J Trop Med Public Health. 1986;17:579-81.
29. Zheng H, Sahai BM, Kilgannon P, Fotedar A, Green DR. Specific inhibition of cell-surface T-cell receptor expression by antisense oligodeoxynucleotides and its effect on the production of an antigen-specific regulatory T-cell factor. Proc Natl Acad Sci USA. 1989:86:3758-62.

30. Falcone FH, Schlaak M, Haas H. In vitro cultivation of Brugia malayi, a parasitic nematode that causes human lymphatic filariasis. Altex. 1995;12: 179-87.

31. Mak J, Lim P, Sim B, Liew L. Brugia malayi and B. pahangi: cultivation in vitro of infective larvae to the fourth and fifth stages. Exp Parasitol. 1983;55:243-8.

32. Ishima Y, Akaike T, Kragh-Hansen U, Hiroyama S, Sawa T, Suenaga A, et al. Snitrosylated human serum albumin-mediated cytoprotective activity is enhanced by fatty acid binding. J Biol Chem. 2008;283:34966-75.

33. Smith HL, Paciorkowski N, Babu S, Rajan TV. Development of a serum-free system for the in vitro cultivation of Brugia malayi infective-stage larvae. Exp Parasitol. 2000:95:253-64.

34. Smith HL, Rajan TV. Tetracycline inhibits development of the infective-stage larvae of filarial nematodes in vitro. Exp Parasitol. 2000;95:265-70.

35. Hollands C. The animals (scientific procedures) act 1986. Lancet. 1986; 328(8497):32-3.

\section{Ready to submit your research? Choose BMC and benefit from:}

- fast, convenient online submission

- thorough peer review by experienced researchers in your field

- rapid publication on acceptance

- support for research data, including large and complex data types

- gold Open Access which fosters wider collaboration and increased citations

- maximum visibility for your research: over $100 \mathrm{M}$ website views per year

At BMC, research is always in progress.

Learn more biomedcentral.com/submissions 